\title{
Home Equity Insurance \& The Demise Of Home Value Insurance Corporation
}

\author{
Zachary A. Smith, Saint Leo University, USA
}

Alan Harper, South University, USA

\begin{abstract}
This study uses the demise of the Home Value Insurance Company (HVIC) to explore whether the concept of home equity insurance is implementable. Shiller, R. and Weiss, A. (1999) and Goetzmann, W., Caplin, A., Hangen, E., Nalebuff, B., Prentce, E., Rodkin, J., Spiegel, M. and Skinner, T. (2003) have provided a platform to evaluate this concept by questioning whether a product that allows homeowners to transfer the risk associated with a decline in housing prices should be structured as insurance. This study explores the cost associated, in the U.S. Real Estate Market, with this risk transfer process in the pre and post mortgage crisis periods by simulating the cost of insurance using the theoretical pricing of ATM (at the money) put options based upon the Black Scholes Option Pricing Model from 1989 to 2013. As the U.S. Housing Market transitioned from the pre-crisis to the post-crisis periods the hypothetical breakeven cost of insurance increased from $0.60 \%$ to $20.85 \%$ of the starting value of the index. The demise of HVIC seems to be a cautionary tale: Given the recent changes in the underlying dynamics of the U.S. Real Estate Market it does not seem prudent (for insurers) to use insurance contracts to transfer the risk associated with a decline in the value of U.S. Residential Equity Wealth.
\end{abstract}

Keywords: Home Equity Insurance; Home Value Insurance Corporation; Black Scholes Option Pricing Model; Simulation

\section{INTRODUCTION}

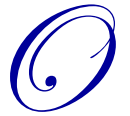

n May 14, 2011, Jason Zweig, in his Wall Street Journal column The Intelligent Investor, wrote a short article titled 'Hedging Your Home Value: The Greatest Idea Never Sold'. The idea of structuring a product that would provide investors with protection against a fall in the market price of their home is not new; however, the concept seemed to be having problems gaining traction in the marketplace until a firm Home Value Insurance Company established an insurance company that allowed homeowners to transfer the risk of a potential loss in the value of their home to a third party. Caplin, Goetzmann, Hangen, Nalebuff, Prentice, Rodkin, Spiegel, and Skinner (2003-Reffered to as CGHNPRSS 2003, hereafter), stated that the first home equity insurance program was started in 1966 to protect: "military personnel and civilian contractors from loss in home value caused by the closing of nearby military installation" (p. 5). Until Home Value Insurance Company started issuing policies, home equity assurance had been provided on a limited basis by municipalities. The two programs that have been explored in previous papers are the programs started in Oak Park, IL in 1977 (see: CGHNPRSS 2003 and McKenzie \& Ruby 2002) and Syracuse, NY in 2002 (see: CGHNPRSS 2003). This paper will evaluate whether the concept of home equity insurance is feasible.

\subsection{The Case}

The Home Value Insurance Company (HVIC) was formed on June 14, 2011 as a property and casualty insurance business in the state of Ohio (Taylor 2012a, pgs. 2-3). On September 14, 2011, the company was licensed to sell home equity insurance in the State of Ohio; thereafter, the company was licensed to sell home equity insurance products in the following states: (a) Oklahoma on December 23, 2011, (b) Georgia on February 8, 2012, (c) Arizona on April 6, 2012, (d) Indiana on February 10, 2012, (e) Louisiana on February 23, 2012, (f) Oregon on May 4, 2012, and (g) Texas on March 8, 2012 (Talyor 2012a, pg. 4). From September 28, 2011 to June 29, 2012, 
Home Value Insurance Company issued 219 insurance policies in Ohio (137), Oklahoma (11), and Georgia (23), which generated $\$ 31,347$ of premium income - the company did not sell any policies in the remaining states for which it had a license (Taylor 2012a, pg. 5).

From December 11, 2011 to June 20, 2012, the company’s reported surplus (i.e. Capital and Surplus) fell from $\$ 7,948,857.00$ to $\$ 2,782,290.00$ (Taylor 2012a, pg. 8), which was problematic because the Ohio Rev. Code 3929.011 requires a stock insurance company to maintain capital and surplus of not less than $\$ 5,000,000$. Since the company no longer maintained the statutory level of surplus, the company's Board of Directors consented to a 'rehabilitation plan', on August 28, 2012 (Taylor 2012a, pg. 9). Under this rehabilitation plan, the commissioner of insurance would take over the company, dissolve the company, and distribute the remaining capital to the shareholders of the company. On September 28, 2012 a rehabilitation plan was filed in the Court of Common Pleas, Franklin, $\mathrm{OH}$ by the Ohio Superintendent of Insurance, which provided a plan for the liquidation of the companythis was necessary because the structure of the insurance policies were annually renewable contracts, renewable for a period of at least nine consecutive years (Taylor 2012a, p. 5); therefore, the policies could not be cancelled unless the rehabilitation order was filed.

The terms of the rehabilitation plan seemed to be more than fair and equitable to the policy holders. Structurally, the purchasers of a home equity insurance plan, as a result of the rehabilitation process on September 28, 2012, could forgo paying premiums (Taylor 2012a, p. 20) and would receive, on November 19, 2012, a check equal to the greater of: (a) A return of all premiums paid to HVIC prior to September 27, 2012, (b) the amount of the policy holder's indexed claim level, which was calculated by, first, taking the starting index level subtracting the ending index level and dividing the result by the start of the index, second, multiplying this result by the protected home value, and, third, subtracting the five percent deductible (see Taylor 2012a, p. 23), or (c) a payment of $\$ 500.00$ (Taylor 2012a, pgs. 20-21). The total amount of payments to policyholders was estimated at $\$ 220,121.38$, based upon the criteria previously presented in this paragraph. According to Taylor (2012b), immediately after the rehabilitation plan was submitted the HVIC mailed plan payments out to policy holders and otherwise implemented the rehabilitation plan (p. 2); thereafter, the Ohio Superintendent of Insurance (i.e. the Rehabilitator) filed an amendment to the previously referenced document (i.e. Talyor 2012a) to "terminate the rehabilitation and this case and make other provisions necessary to discharge the Rehabilitator" (Taylor 2012b, p. 1), since the HVIC completed Phase 4 of the Rehabilitation Plan, which was the Implementation of the Plan (Taylor 2012a \& Taylor 2012b).

HVIC failed in its first year of business, which will probably provoke insurance regulators, prospective insurers, and consumers to question whether the idea of home equity insurance is an implementable idea. Many questions remain and this analysis will examine the circumstances surrounding the failure of this firm and the basic idea of home equity insurance as a product. The remainder of this section will discuss the development of the concept of home equity insurance.

\subsection{Home Equity Insurance}

The questions that permeates a discussion of what 'could have been' when you are analyzing a firm that failed to survive a year as a corporation (i.e. losing over $\$ 5$ million in the first year of operations) are as follows: (a) Is there a need for this product or service and (b) How should this product be structured?

According to a report put out by The Joint Center for Housing Studies of Harvard University (2012; hereafter TJCHSHU 2012), the value of new and existing home sales from 2010 to 2011 averaged \$717 Billion per Annum (p. 8). Furthermore, using the estimated number of housing units from Mazur, C. and Wilson, E. (2001) of 131,704,790 million units (p. 4) and taking the TJCHSHU (2012) highest and lowest median existing sales estimate of homes across the U.S. of $\$ 178,600$ and $\$ 156,500$, respectively, should provide a very rough estimate for the total value of residential real estate in the U.S., which exceeds $\$ 20$ Trillion. According to data obtained from the Federal Housing Agency's House Price Index from the second quarter of 2007 to the third quarter of 2012 the average home purchase price was down approximately $15.95 \%$. The researchers provided the preceding numbers to illustrate a point, if the real estate market suffered another crisis like the one that occurred in the 2007 to 2008 time frame, the magnitude of the losses in the system could equate to losses in excess of $\$ 3.19$ trillion in residential equity wealth. 
The preceding paragraph provided an illustration of the potential impact that another event similar to what occurred from 2007 to 2008 could have on the value of residential real estate prices; therefore, it is assumed that there could be a market for a product that would allow you to transfer the risk associated with a decline in the value of your home price. The question that is relevant after establishing the market's need for this product to exist is what should a product meant to enable the purchasers of a home to transfer the risk associated with a decline in the value of their home price to a third party look like? In the ensuing paragraphs, the researchers will analyze three of the available options, which are: (a) Municipality Run, (b) Derivative Contracts, and (c) Insurance.

\subsection{Municipality Run Plans}

In September of 1978 the Equity Assurance Program was initiated in a suburb of Chicago, Oak Park, as a way to prevent what the authors refer to as 'white flight' and a "fear of having the value of your house decline because of this integration", which in this case could potentially occur as a predominately white community begins to experience diversity in terms of the community's residents (McKenzie \& Ruby, 2002, p.16). McKenzie and Ruby (2002) applied social science theory and discussed this fear in terms of 'succession' or 'tipping points' and stated that "a community that rapidly changes its racial composition from one majority group to another-typically from all white to nearly all black — is said to have 're-segregated"' (McKenzie \& Ruby, 2002, p. 3) - this re-segregation effect was what the Oak Park Strategy was designed to avoid. The Equity Assurance Program was designed to allow citizens to transfer the risk associated with the racial integration occurring in their community-the risk that was transferred was the risk of a potential decline in the value of their home.

Another example of a program initiated to allow the prospective homeowner to transfer the risk associated with the potential decline in home prices occurred in Syracuse, NY in 2002, which was referred to as Home Equity Protection (HEP). Prior to the introduction of this risk transfer mechanism the city of Syracuse had experienced significant population losses over the preceding 50 years and significant declines in the real value of home prices while the nation enjoyed, in general, an appreciation in the value of their homes. According to CGHNPRSS (2003):

- $\quad$ From 1990 to 2000, the city of Syracuse lost 10\% of its population (p. 3).

- $\quad$ Home prices in Onondaga County, of which Syracuse is located, dropped 16.5\% (p. 3).

- $\quad$ One half of homeowners that sold their homes in 1997 took a loss on the sale (p. 3).

- $\quad$ Less than $40 \%$ of the occupants of homes in the city of Syracuse own their homes (p. 3).

CGHNPRSS (2003) stated that The Home Equity Protection Program was started with a \$5 Million U.S. Department of Housing and Urban Development (HUD) grant obtained by Congressman Walsh (p. 21). The purpose of this program was also to allow home purchasers to transfer the risk associated with a potential decline in the value of the program participants' homes. Unlike the preceding case, the risk identified to provoke such a risk transfer was the general decline of the Syracuse economy and the ensuing deterioration in the value of homes in a depressed region.

The two programs presented in the proceeding paragraphs demonstrate two home equity protection programs that have been initiated to allow home owners to transfer the risk of a decline in the value of their home. Both programs where initiated as a counter balance to potential problems faced by the two municipalities: (a) Integration of races in Oak Park and (b) Depressed economic climate in Syracuse. In one case, the funding for the program was generated through tax revenue; the other was made possible through a HUD grant. The participation rates of home owners in these programs have been low and do not seem to be sustainable on a broader scale. There was an additional problem with both programs: the degree of concentrated risk that each program takes on is unacceptable because there is no geographic diversification in terms of coverage areas.

\subsection{Derivative Contracts}

Case, K., Shiller, R., and Weiss, A. (1991) presented an argument to establish cash settled futures and options markets for real estate - these markets would provide investors with opportunities to further diversify their investment portfolios and construct better hedges against a fall in the price of their home (pgs. 1-2). The authors seemed to have gained some traction in this regard in terms of establishing futures and options markets for regional 
real estate markets, to date they have been able to establish traded futures and options for 10 major markets (i.e. Boston, Chicago, Denver, Las Vegas, Los Angeles, Miami, New York, San Diego, San Francisco, and Washington D.C.) as well as a composite index for the U.S. (CME Group, 2008). The creation of regional indices that track the local market's price movements provide a baseline for institutions that would be willing to provide insurance to the public; however, these institutions would still likely have to limit themselves to writing policies in the aforementioned regions to insure that they are properly hedged.

Hedging a home's price against the aggregate price movement of an entire city may not provide an accurate hedge. For example, New York City has five boroughs (i.e. Manhattan, The Bronx, Brooklyn, Queens, and Staten Island), it is unlikely that a perfect hedge for real estate price changes occurring in The Bronx or Staten Island is going to be generated by purchasing protection against price movements in the five boroughs-the key here is that the indices need to be calculated at the zip code or tract level. Another potential problem of using derivatives contracts to hedge the value of a home without the help of an intermediary is that according to Shiller, R. \& Weiss (1999) "in the public mind, there is a sharp distinction between speculative assets and insurance... a home equity insurance policy that too much resembles a speculative asset may not be accepted by the public or regulators" (p. 30). Potential customers and regulators prefer the concept of insurance over the use of derivative contracts as a risk transfer mechanism.

\subsection{Insurance}

CGHNPRSS (2003), in the pilot project that participated in development of the municipality project initiated in Syracuse, NY, found that the insurance regulator had problems with the product being referred to as 'insurance' - there are two reasons that were cited. The first was whether the homeowner could meaningfully influence the outcome of what is being insured (CGHNPRSS, 2003, p. 25). The second was in reference to how the contract payouts were determined based upon a real estate index (CGHNPRSS, 2003, p. 25). The next two paragraphs will discuss the two problems sequentially.

The first problem was that insurers were concerned with the morale hazard problem that might arise if the insured are allowed to influence the outcome of what is being insured (CGHNPRSS, 2003, p. 25). The problem is that the insured determines when to collect on the insurance, meaning that the fact that they had the contract may influence their decision to sell (CGHNPRSS, 2003, p. 25); the structure of the contracts that have been formulated and approved by insurance regulators in Oklahoma, Georgia, Arizona, Indiana, Louisiana, Oregon, and Texas seem to have looked past this potential hazard; however, we can liken this to an individual that has healthcare insurancethe fact that they have healthcare insurance may induce them to use the insurance more than would be otherwise necessary.

The second problem has to do with the way in which the insurance payout is typically calculated. This problem arises as a result of constructing a contract that pays claims based upon the actual value of the physical property owned by the contract holder - this may lead to another morale hazard problem. If, the insured has a contract that entitles them to receive the full value of the purchase price of the home, they have no incentive to attempt to sell the house for the fair market value of the home (since the insurance will pay them the difference between the sale price and the purchase price); therefore, the insured may not invest in the necessary upkeep of the house or they may devalue the home without considering the potential resale effects their actions have. To overcome this obvious problem, most providers of 'Home Equity Contracts' estimate the loss based upon a local market index, according to CGHNPRSS (2003) regulators in New York held that home equity insurance based upon a local market index is not insurance, because the "homeowner does not have any material interest in the local real estate index" (p. 25). This statement or conclusion seems appropriate, but it seems as though, at the local level, viewed through the lens of a homeowner, changes in the value of a local real estate index is not immaterial.

\subsection{Summary}

There are three key points that were covered in this section that should be restated: (a) Is the municipal solution the right form of risk transfer, (b) Could the use of derivatives facilitate, in its entirety, the risk transfer process, and (c) Should the product, that facilitates the transfer of risk, be referred to as insurance? It seems obvious 
that a private market solution that affords homeowners to transfer the risk of a decline in the value of their property is a better mechanism than a plan run by a localized governmental institution; for example, private market solutions are typically more efficient allocators of capital and localized governmental programs would expose the program to localized concentrated risk. CGHNPRSS (2003) concluded that the variant of a Home Equity Assurance program or Home Equity Protection (HEP) was not an insurance product; it was a stand-alone product (p. 27), there is still dissention among the competitors that are attempting to offer such a product, the question remains: is it insurance or is it something else (CGHNPRSS, 2003, p. 27)?

\section{RESEARCH AND METHOLDOGY}

\subsection{Simple Linear Regression Analysis}

Ordinary Least Squares (OLS) regression analysis is applied to this study to determine both the longer-term trends associated with housing prices and the structural break between the pre-crisis and post-crisis period. To conduct a regression analysis we begin with an assumption that the variable Time has an influence over the Case Shiller 10-City Home Price Index (HPI); this study follows this initial assumption up with the assumption that the relationship between Time and HPI has a random component $u$, formally:

$H P I_{i}=\hat{\beta}_{i}+\hat{\beta}_{1}$ Time $_{i}+u_{i}$, with the following assumptions:

Equation 1

$$
\begin{array}{ll}
\mathrm{E}\left(\mathrm{u}_{\mathrm{i}}\right)=0 & u \text { has a mean of } 0 \text { for all } i \\
\mathrm{E}\left(\mathrm{u}_{\mathrm{i}}^{2}\right)=\sigma_{\mathrm{u}}^{2} & u \text { has the same variance for all } i \\
\mathrm{E}\left(\mathrm{u}_{\mathrm{i}} \mathrm{u}_{\mathrm{j}}\right)=0, \mathrm{i} \neq \mathrm{j} & u \text { is not correlated across observations }
\end{array}
$$

\subsection{Cubic Regression Analysis}

Statistical problems associated with forecasts of housing prices as the U.S. Housing Market transitioned from the pre-crisis period to the post crisis period have been documented. Goetzmann, Peng, and Yen (2012) spent considerable time examining the predictability of the HPI, they determined that forecasts of home price changes were flawed because the indices did not consider the potential effect of an illiquid housing market and data on the performance of the indices during a period of relatively illiquid housing markets is scarce. This means that as the housing market went from the pre-crisis period to the post-crisis period, estimating changes in the home price index becomes a difficult undertaking. The cubic regression function is defined as follows:

$H P I_{i}=\hat{\beta}_{i}+\hat{\beta}_{1}$ Time $_{i}+\hat{\beta}_{2}$ Time $_{i}^{2}+\hat{\beta}_{3}$ Time $_{i}^{3}+u_{i}$

Equation 2

This project uses both functions to describe the changes in the HPI over Time.

\subsection{Cacluation of Premiums}

After the return series was generated, the researchers used the Black Scholes Option Pricing Model to generate an idea of what the appropriate cost of risk transfer might look like. The cost of a Put Option on the current average $H P I$ is estimated as follows:

$$
\begin{aligned}
& P(S, t)=K e^{-r(T-t)}-S+C(S, t), \text { where } \\
& C(S, t)=N\left(d_{1}\right) S-N\left(d_{2}\right) K e^{-r(T-t)} \\
& d_{1}=\frac{1}{\sigma \sqrt{T-t}}\left[\ln \left(\frac{S}{K}\right)+\left(r+\frac{\sigma^{2}}{2}\right)(T-t)\right] \\
& d_{2}=d_{1}-\sigma \sqrt{T-t}
\end{aligned}
$$


$\mathrm{N}(\cdot)$ : Is the cumulative distribution function of the standard normal distribution

T-t: $\quad$ Is the time until maturity

S: $\quad$ Is the spot price of the Housing Index

$\mathrm{K}$ : Is the strike price of the Housing Index

$r: \quad$ Is the risk free rate of return

$\sigma: \quad$ Is the volatility of returns of the underlying asset

The researcher used an examination period of a 12 month return series, calculated the standard deviation of that return series and multiplied the standard deviation by the squareroot of 12 to annualize the monthly standard deviation and thus, generate an estimate for $\sigma$. The risk free rate of return, $r$, is set to set to zero in this analysis due to the length of the option period and to provide a worst case scenerio of what the costs of providing insurance to homeowners during this time frame would be. $T$ is set to 30 years over examination period (i.e. the cost of a 30 -year put option with no risk free rate of return).

\subsection{Simulation of Gains \& Losses}

To simulate gains and losses the researchers used the historical series from the HPI from April of 1988 to December 2013. The index was used to calculate the theoretical price of a put option on the starting value of the home index in month $i$. The monthly standard deviation of the price return of the series is observed over a 12 -month cycle to calculate the volatility of the option. The monthly standard deviation is annualized by multiplying the monthly standard deviation by the square root of the 12 monthly observations.

After the theoretical put options were calculated the researchers ran a simulation to identify at what premium a hypothetical firm would reach a breakeven point across the entire sample consisting of a 10-year period. The procedure is defined as follows: if the owner of the contract does not exercise in the first period it is assumed that they will exercise in the second period and so on and so forth. To run this simulation the sample time horizon was partitioned into three samples. The first sample consisted of the entire observation period and the remaining samples were broken into two time periods: (a) Pre-Financial Crisis and (b) Post-Financial Crisis. Returns for the hypothetical insurer were simulated for: $1,2,3,4,5,6,7,8,9$, and 10 years on a rolling basis after the premiums were written.

\section{DATA \& DESCRIPTION OF VARIABLES}

Data on the HPI was obtained on the FRED database (maintained by the Saint Louis Federal Reserve). The begin to construct a model that could be used to price the cost of providing insurance against a decline in the average housing prices across the United States the researchers took monthly estimates of the average home price from April 1996 to January 2012. The price series was used to create a return series calculated as the holding period return. The following assumptions were made to obtain the estimated cost of insurance based upon an ATM (at the money) put option calculated using the Black Scholes Option Pricing Formula: (a) The annualized volatility of the home price index could be approximated by multiplying the square root of the monthly standard deviation by 12 and (b) The researchers used a risk free rate of return of zero percent.

\subsection{U.S. Housing Prices}

Figures 1, 2, and 3 provide an illustration of how the HPI changed as the U.S. Housing Market transitioned from the pre-crisis to the post-crisis period. The figures illustrate that there are two distinctive periods. The first trend, lasting from 1988 to 2006, was a period of consistently positive growth in the average housing price in the U.S.; since that time, there seems to be a trend of declining housing prices in the U.S. (i.e. from 2006 to 2013). 


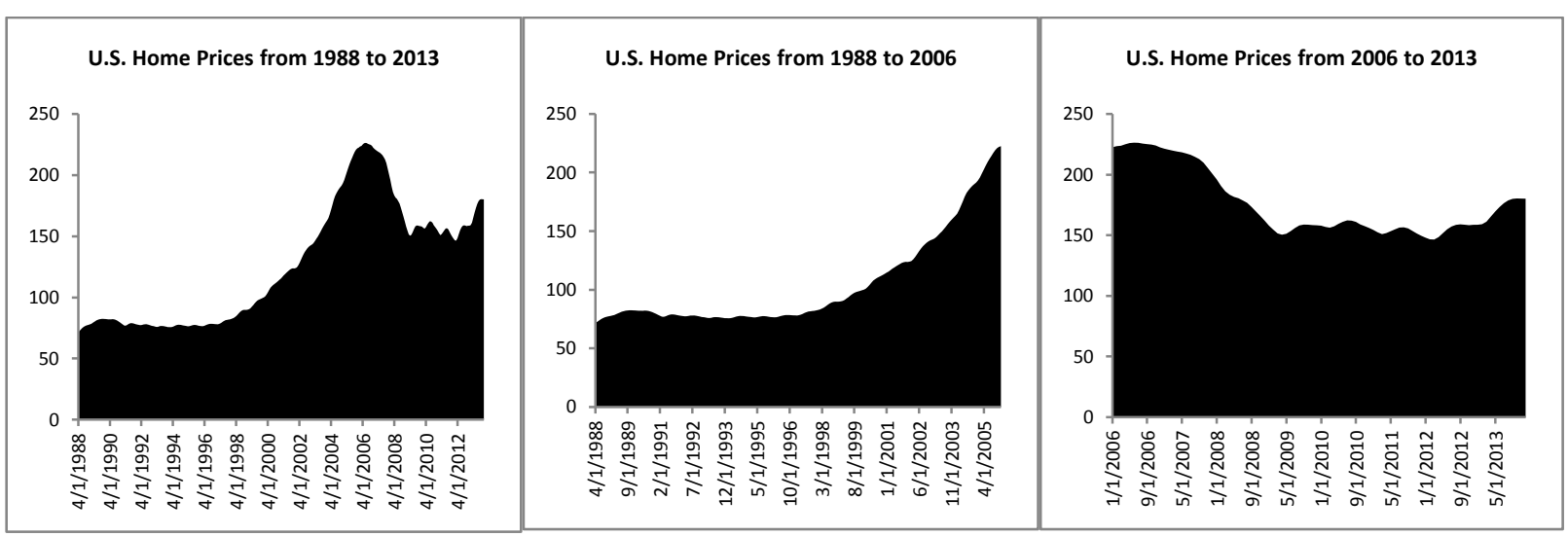

Figures 1, 2, \& 3: Figure 1 depicts the value of the HPI from 1988 to 2013. Figure 2 depicts the value of the HPI from 1988 to 2006. Figure 3 depicts the value of the HPI from 2006 to 2013. The data used to produce these graphs was obtained from the Federal Reserve Bank of St. Louis (FRED) database. The data series plotted on this figure is the HPI (SPCS10RNSA), the index is set to 100 on January 2000. The data was obtained on March 15, 2014.

Figures 1, 2, \& 3: Average Home Prices in the U.S.

This study does not intend to identify the causes of the collapse in housing prices; however, Mikhed, V. and Zemcik, P. (2009) presented evidence that the financial collapse was caused by a departure in housing prices from fundamental determinates of the level of housing prices. Mikhed et al. identified two bubbles in the prices of U.S. housing prices using quarterly data from 1980 to 2008; the first lasting from 1980 to 1990 and the other lasting from 2000 to 2005 . They concluded that the correction experienced since 2005 seems to align the price of housing with construction costs and other fundamental determinates of housing prices (i.e. Rent, Personal Income, Mortgage Interest Rates, and Stock Market Prices).

If this is true and the 'bubble' has burst, a question remains: will the dynamics that governed the trend of housing prices return to their previous trend or will the increase in the volatility experienced recently persist. Case, K. (2008) offered some interesting generalizations about housing prices and their general tendencies; he stated that finding a bottom after a market correction is influenced by the following variables: (a) Housing prices are heterogeneous and hard to measure, (b) Housing prices are subject to inertia and sticky downward, (c) Housing markets have traditionally been quantity clearing markets, and (d) Housing market performance depends on credit markets and monetary policy (p. 171). Case, K. (2008) seems to conclude that prices will stop changing once they reach their fundamental value, but fundamental values are only reached when there is a balance between what people that have the resources to pay for a good, a desire to pay for that good, and what that good is available for sale in the marketplace (p. 191). 


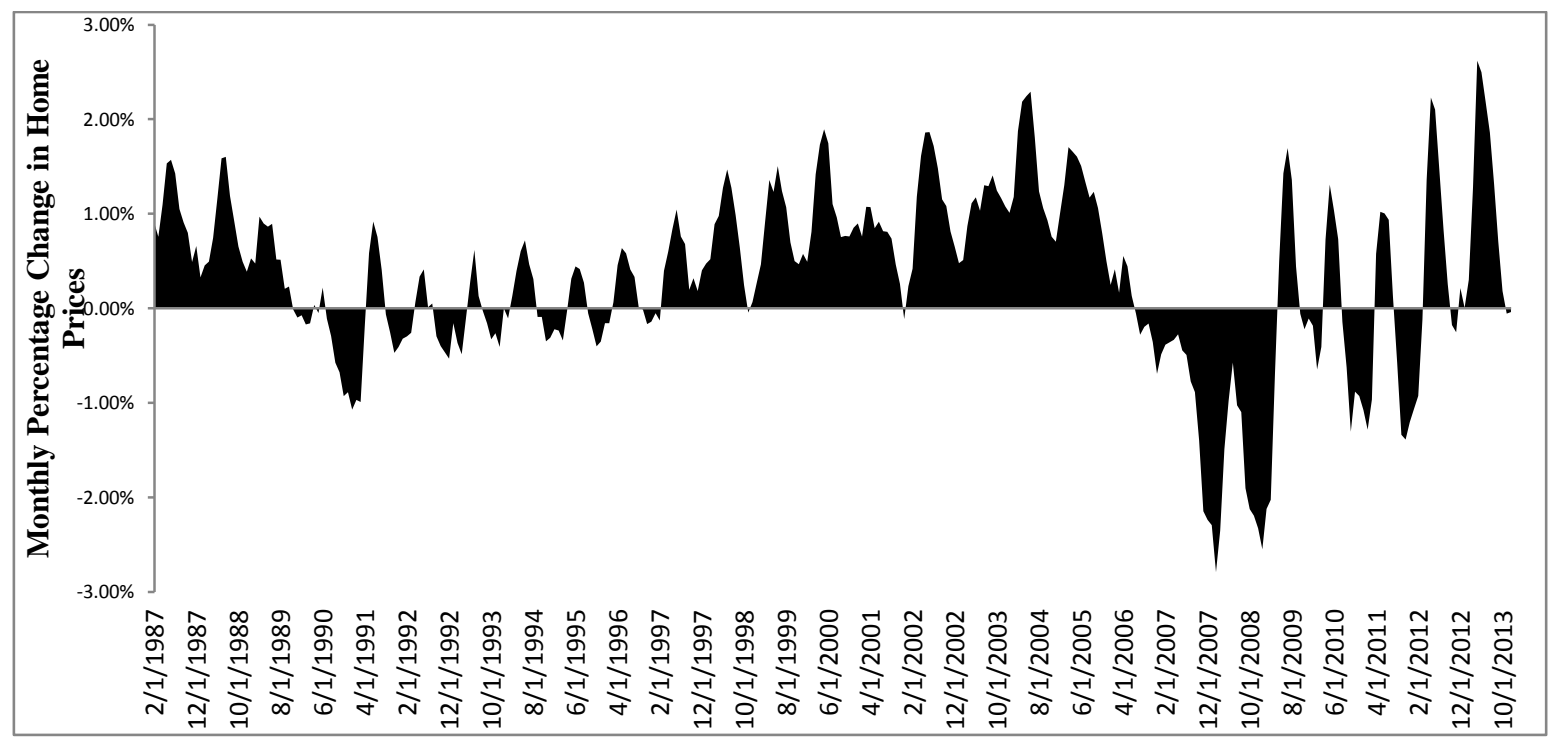

Figure 4: Figure 4 depicts the percentage change in the value of the HPI from February 1987 to December 2013. The return series is calculated as follows: $R_{i, t}=\left(P_{i, t}-P_{i, t-1}\right) / P_{i, t-1}$.

Figure 4: Percentage Change in the HPI from February 1987 to December 2013

Figure 4 graphically presents the monthly percentage changes in the HPI from February 1987 to December 2013 . A visual examination of Figure 4 seems to illustrate that the monthly return series has become more volatile as the housing crisis began. Prior to the crisis the series seemed to be more stable and was biased towards increases in the aggregate level of housing prices. Since the crisis, the series seems to have become more unstable and does not seem to exhibit any clear trend.

Table 1 presents descriptive statistics for the changes in the level of the index. To generate an understanding of the changing dynamics of the underlying series, the researchers segmented the series into two components: (a) a pre-market crisis series (1989-2006) and (b) a series that includes the crisis. The average monthly change in the value of the index in the period preceding the market crisis was $0.54 \%$ and, since the crisis began, the average monthly change in the index has plummeted to $-0.24 \%$. Additionally, the volatility of the underlying series has increased markedly. Prior to the start of the crisis the standard deviation of the monthly return series was $0.68 \%$, since the crises the standard deviation has almost doubled to $1.21 \%$. It is evident that the underlying volatility of the price series has increased.

Table 1: Descriptive Statistics

\begin{tabular}{lccccccc}
\hline \multicolumn{2}{l}{ Percent Change in $H P I$} & & & & \\
\hline Time Period & Average & Median & Standard Deviation & Minimum & Maximum & Skewness & Kurtosis \\
\hline 1989 to 2013 & $0.31 \%$ & $0.40 \%$ & $0.94 \%$ & $-2.79 \%$ & $2.62 \%$ & -0.51 & 0.69 \\
1989 to 2006 & $0.54 \%$ & $0.51 \%$ & $0.68 \%$ & $-1.07 \%$ & $2.29 \%$ & 0.12 & -0.43 \\
2007 to 2013 & $-0.21 \%$ & $-0.21 \%$ & $1.21 \%$ & $-2.79 \%$ & $2.62 \%$ & 0.1 & -0.25 \\
\hline
\end{tabular}

Table 1: The first portion of this table covers the entire observation period, whereas the second two sections in this table covers the period prior to the housing market collapse (i.e. Period 1989 to 2006) and the period after the start of the collapse (i.e. Period 2007 to 2013). The table displays summary statistics on the performance of the HPI.

\subsection{Premium Structure}

This section outlines how the structure of premiums would change as a result of the changes in the dynamics of housing prices. The researchers used ATM (at the money) put options to approximate the cost of protecting the homeowner against a fall in the average value of home prices across the U.S. Figure 5 presents the changes in the approximate cost of protection during the 1988 to 2013 period. As illustrated in Figure 5 there is a dramatic change in the cost of protection that occurred at the beginning of the housing market crisis. Figures 6 and 7 visually illustrate the change in the cost of protection as the housing market crisis occurred. 


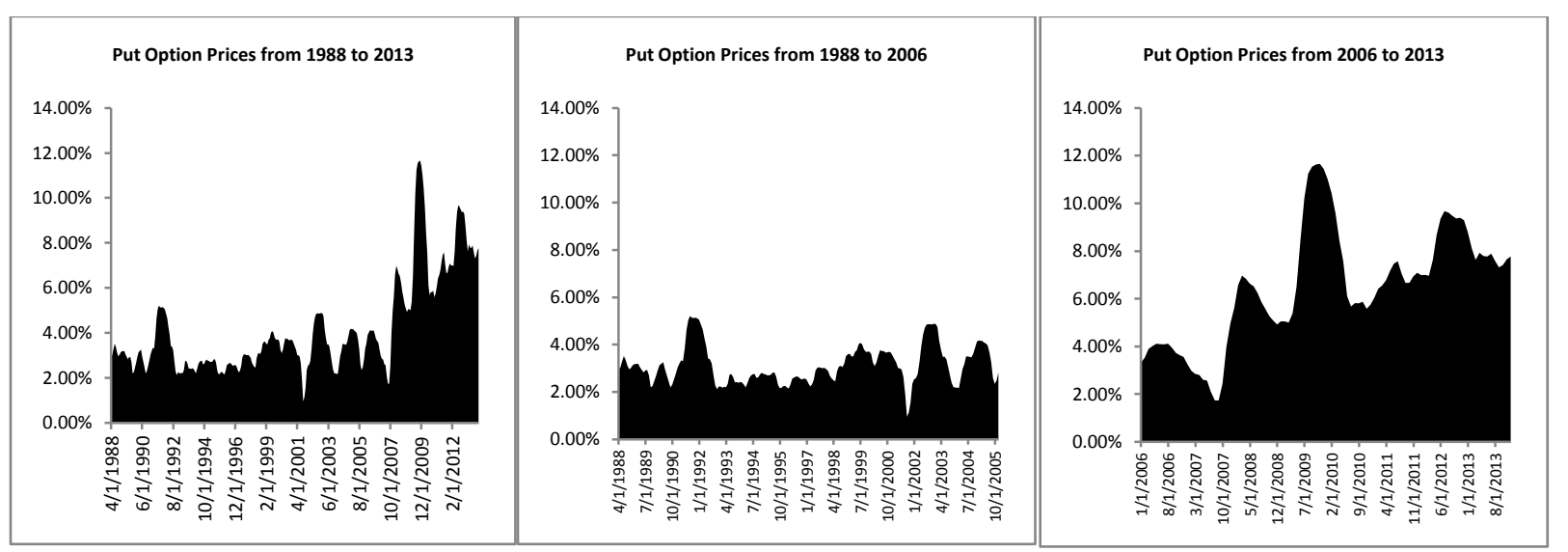

Figure 5, 6, \& 7: Figure 5 depicts the estimated value of a ATM put option on the previous value of the average home price in the U.S. over the entire sample period. Figure 6 depicts the estimated value of a ATM put option on the previous value of the previous month's average home price in the U.S. during the pre-crisis period. Figure 7 depicts the estimated value of a ATM put option on the previous month's value of the average home sales price in the U.S. during the post-crisis period. The put option prices were calculated using the Black Scholes Option Pricing Model: (a) Estimates of volatility were calculated using a trailing 12-month return series and calculating the annualized standard deviation of the return series by multiplying the monthly standard deviation by the square root of 12 , (b) The risk free rate of return was set to zero, and (c) The coverage period is 30 years.

Figures 5, 6, \& 7: Calculation of ATM Put Options on the Home Price Index

Table 2: Descriptive Statistics

\begin{tabular}{lccccccc}
\hline Cost of Put Options & \multicolumn{1}{c}{} & & & & \\
\hline Time Period & Average & Median & Standard Deviation & Minimum & Maximum & Skewness & Kurtosis \\
\hline 1989 to 2013 & 5.67 & 3.75 & 4.24 & 1.16 & 18.49 & 1.1 & 0.25 \\
1989 to 2006 & 3.29 & 2.54 & 1.68 & 1.16 & 8.2 & 1.36 & 1.04 \\
2007 to 2013 & 10.97 & 10.44 & 3.31 & 3.72 & 18.49 & 0.25 & -0.15 \\
\hline
\end{tabular}

Table 2: Table 2 presents the cost of insurance on the HPI. The first section illustrates the cost of insurance for the 1989 to 2013 period, the second section illustrates the cost of insurance for the pre-housing market collapse period, and the third section presents the cost of insurance after the start of the housing crisis.

Table 2 illustrates that the cost of protection increased significantly as the U.S. Economy moved from the pre-crisis period into the period that covered the crisis and beyond. The median cost to insure the value of a home increased threefold and the standard deviation of the insurance cost increased markedly. The distribution of the premiums of insurance contracts changed significantly as the U.S. Economy experienced a significant downturn. It seems as though the distribution of contracts was significantly positively skewed prior to the crisis; therefore, it is assumed that what now seems to be relatively tame shocks in the value of home prices caused the distribution of the premiums to be positively skewed. The post-bubble period seems to have a relatively normal or stable distribution with a significantly larger average observations and the volatility of the price series increases significantly. The increase in the volatility and the average premium causes the entire sample to be skewed positively and the average premium over the sample as well as the standard deviation of the price series increases significantly.

Table 3 relates the information on index levels presented in Table 1 to the cost of insurance presented in Table 2. The estimated cost of protection as a percentage of the starting index price doubles as we move from the pre-mortgage crisis period into the crisis and beyond; moreover, the standard deviation in the cost of insurance doubles. It would be inherently more difficult to set a standard price on insurance when the average cost of insurance a percent of the index doubles and oscillates between $1.73 \%$ and $11.65 \%$ in the period following the mortgage crisis compared to a much smaller range of $0.95 \%$ to $5.21 \%$ in the pre-crisis period. 
Table 3: Descriptive Statistics

\begin{tabular}{lccccccc}
\hline Percent of Index & & & & & & \\
\hline Time Period & Average & Median & Standard Deviation & Minimum & Maximum & Skewness & Kurtosis \\
\hline 1989 to 2013 & $4.16 \%$ & $3.38 \%$ & $2.17 \%$ & $0.95 \%$ & $11.65 \%$ & 1.51 & 1.77 \\
1989 to 2006 & $3.12 \%$ & $3.00 \%$ & $0.80 \%$ & $0.95 \%$ & $5.21 \%$ & 0.68 & 0.34 \\
2007 to 2013 & $6.48 \%$ & $6.60 \%$ & $2.43 \%$ & $1.73 \%$ & $11.65 \%$ & 0.14 & -0.47 \\
\hline
\end{tabular}

Table 3: Table 3 presents the percentage of the cost of insurance based upon the current level of the HPI. The first section illustrates percentage cost of insurance for the 1989 to 2013 period, the second section illustrates the percentage cost of insurance for the pre-housing market collapse period, and the third section presents the percentage cost of insurance after the start of the housing crisis.

With an understanding that the premium structure as well as its volatility increases significantly as the post-bubble period is added to the pre-bubble period, it seems relevant to evaluate how the increases in the premium structure influences the potential cost to the consumer. Over the entire period the cost of protection, as measured for through the calculation of an ATM put option, is $4.16 \%$, which is a percentage point greater than the cost of insurance during the pre-bubble period. It is obvious that the period including the crisis caused the average cost to increase; in addition, the dramatic increase in the standard deviation of the percentage cost of protection implies that offering a standard pricing structure is impractical.

\section{EMPIRICAL RESULTS}

\subsection{Changes In The Structural Relationship Between Time And Housing Prices}

Table 4: Regression Results

\begin{tabular}{llll}
\hline \multicolumn{2}{l}{ Time Series Analysis of Changes in the Index Level } & & \\
\hline Statistic & Entire Period & Pre-Crisis & Post-Crisis \\
\hline Intercept & $-422.18^{* * * *}$ & $-509.56^{* * *}$ & $1137.14 * * *$ \\
Standard Error & 21.80 & 28.85 & 88.07 \\
Beta & $0.0149^{* * *}$ & $0.0173 * * *$ & $-0.0239^{* * * *}$ \\
Standard Error & 0.0006 & 0.0006 & 0.0022 \\
$R^{2}$ & 0.6747 & 0.6824 & 0.5588 \\
$N$ & 309 & 213 & 96 \\
\hline
\end{tabular}

Table 4: Table 4 illustrates the change in the relationship between Time and the HPI. The first regression was run including all observations obtained from April 1, 1988 to December 31, 2013. The second regression was run including observations from April 1, 1988 to December 31, 2006 (i.e. Pre-Crisis). The third regression was run using observations from January 1, 2007 to December 31, 2013. *** indicates that the variable was significant using an $\alpha$ of less than .001 .

The preceding regression analysis outlines the findings of the time series regression in which the researchers regressed the HPI on the Time variable. The data was again partitioned into three segments: (a) The Entire Period, (b) Pre-Crisis and (c) Post-Crisis. It is evident that there is a significant change in the beta coefficient as the study moved from the pre-crisis period to post crisis period. To determine if the difference is statistically significant the researchers conducted the following $t$ test: $t=\frac{b_{1}-b_{2}}{\sqrt{s_{b_{1}}^{2}-s_{b_{2}}^{2}}}$, where $\mathrm{b}_{1}(.0173)$ and $\mathrm{b}_{2}(-0.239)$ are estimates for the slope of the regression equation in the pre-crisis period and post crisis period, respectively. The critical value of $t$ for this hypothesis test (given that the degrees of freedom are $n-4$ or 305) is 2.57 and the calculated $t$ statistic is 18.07; therefore, this study finds evidence using an $\alpha$ value of less than .01 that the beta estimates are not equal. Furthermore, the researchers used EVIEWS to run a Chow Test to determine if there is evidence of a structural break in the time series as the U.S. Housing Market transitioned from the pre-crisis to the post-crisis period. The log likelihood ratio is calculated to be 895.524; this study finds that there was a structural break in the series that occurred as the housing market moved from the pre-crisis to post-crisis period $(p$-value $<.001)$.

The assumptions embedded in the simple linear regression analysis as well as those used to conduct the Chow Test have been violated. Figure 8 presents evidence that the errors are serially correlated over time. Stata 8.0 was used to run a Durbin-Watson test to determine if the data had autocorrelation problems, thus violating the assumption that the errors are not correlated across time. The D statistic $(2,309)$ was calculated to be .002 ; therefore, this study finds significant evidence of autocorrelation. 
This Figure Plots the Errors Generate by the Regression Model Over Time

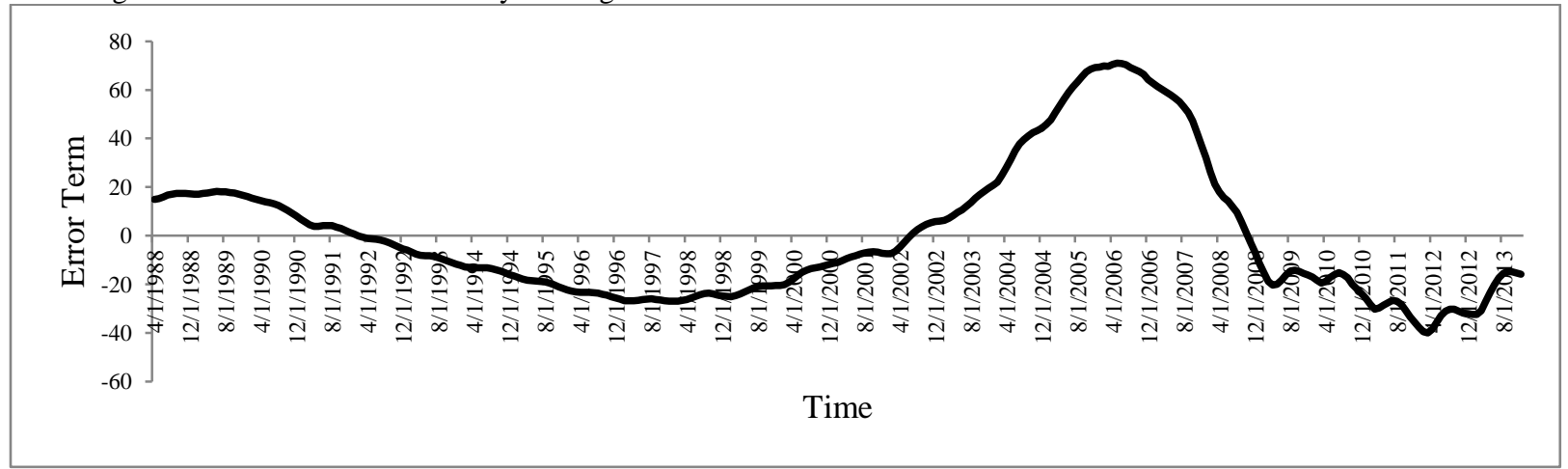

Figure 8: Figure 8 plots the error term generated by a change in the relationship between Time and the HPI. The regression was run including all observations obtained from April 1, 1988 to December 31, 2013.

Figure 8: Error Term

Given that the data series has significant autocorrelation problems and there is significant evidence that the underlying process generating the HPI is nonlinear the researchers used a Cubic Regression Analysis to describe the changes in the index level. As seen in Table 5, the cubic function has a significant $F$ ratio which indicates that the independent variable Time, is a good indicator of HPI for all periods. The modelling procedure used in this analysis is applied as a descriptive measure of how the index has changed over time. The $r$ squared of the cubic function for the entire period, the pre-crisis period, and the post crisis periods are $.847, .993$, and .925 respectively. A comparison of the cubic $r$ squared statistics with the linear $r$ squared statistics from the linear regression analysis are displayed in Table 4 ( $r$ squared statistics: a. entire period: .6747, b. pre-crisis: .6824, and c. post-crisis: .5588), indicate that the cubic function provides a better description of the variation of the HPI over Time.

The fitted curves for all periods are depicted in Figures 9,10 and 11; the cubic function seems to do a good job of describing the changes in the index over the time periods examined.

Table 5: Regression results using the Cubic Function

Time Series Analysis of Changes in the Index Level

\begin{tabular}{llll}
\hline Statistics & Entire Period & Pre-Crisis & Post-Crisis \\
\hline Intercept & $103.390^{* * *}$ & 80.181 & 233.546 \\
Standard Error & 4.456 & 1.070 & 2.724 \\
Time 1 & $-1.493 * * *$ & $-0.005 * * *$ & $-3.742^{* * * *}$ \\
Standard Error & 0.124 & 0.041 & 0.276 \\
Time 2 & $0.016^{* * *}$ & $-0.003 * * *$ & $0.049 * * *$ \\
Standard Error & 0.001 & 0.000 & 0.000 \\
Time 3 & $-3.609 \mathrm{E}-05^{* * *}$ & $2.679 \mathrm{E}-5 * * *$ & $0.000^{* *}$ \\
Standard Error & 0.000 & 0.000 & 0.000 \\
R-Squared & 0.847 & 0.993 & 0.925 \\
Significance F & 0.000 & 0.000 & 0.000 \\
$n$ & 309 & 213 & 96 \\
\hline
\end{tabular}

Table 5: Table 5 illustrates the change in the relationship between Time and the HPI using a Cubic Regression Analysis. The first regression was run including all observations obtained from April 1, 1988 to December 31, 2013. The second regression was run including observations from April 1, 1988 to December 31, 2006 (i.e. Pre-Crisis). The third regression was run using observations from January 1, 2007 to December 31, 2013. *** indicates that the coefficient was significant using an $\alpha$ of less than $.001 \mid * *$ indicates that the coefficient was significant using an $\alpha$ of less than .05 . 
Actual versus predicted plots of the HPI over the Entire Sample, Pre-Crisis, and Post-Crisis Periods
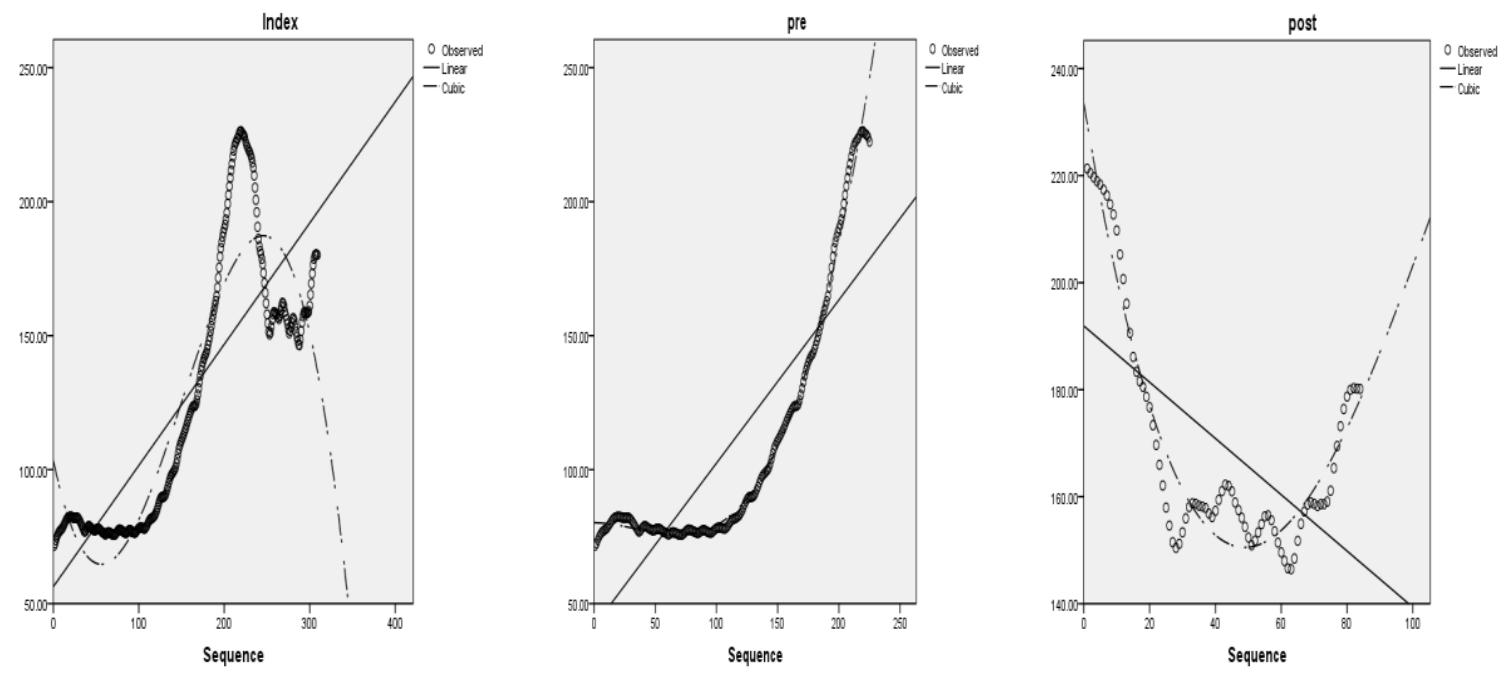

Figures 9, 10, and 11: Figure 9 plots the cubic estimate against the actual level of the HPI over the entire period. Figure 10 plots the cubic estimate of the HPI against the actual value of the HPI over the pre-crisis period. Figure 11 plots the cubic estimate against the actual value of the HPI over the post-crisis period.

Figures 9, 10, \& 11: Observed \& Estimated Plots for the Cubic Regression Analysis

\subsection{Simulation}

Table 6 presents the results of a simulation run to determine, as a fixed percentage of the starting HPI level, the premium necessary for the hypothetical insurer to breakeven on their policies issued during the three sample periods (i.e. Entire Period, Pre-Crisis, and Post-Crisis). To carry out the simulation, the researchers used the HPI, which was partitioned into three segments: (a) The Entire Sample Period (i.e. April 1989 to December 2013, (b) The Pre-Crisis Period (i.e. April 1989 to December 2006), and (c) The Post-Crisis Period (i.e. January 2007 to December 2013). In the simulator, constructed using Microsoft Excel, a fixed rate (i.e. cost of protection) was set in a cell and each month the starting value of the HPI was multiplied by the fixed rate.

Using the data from the previous three sub-samples historical gain / losses were estimated based upon the point movements in the HPI. The researchers estimated index level point changes over 1, 2, 3, 4, 5, 6, 7, 8, 9 and 10 year periods. If the index was above the starting value (i.e. when the hypothetical contract was written) the gains would be retained by the hypothetical insurer and if the index level fell below the initial level of the index, the point change in the index was subtracted from the premium and the gains or losses would be generated.

In the first section of Table 6, the results of the simulation for the entire sample period (i.e. from 1989 to 2013) are displayed. The average premium as a percentage of the index required to breakeven on contracts written was $7.39 \%$ of the value of the index. To put this into perspective, the estimated cost to insure a $\$ 100,000$ house to breakeven over the entire sample period would have been $\$ 7,390$. The breakeven point was found in year 5; therefore, the potential losses experienced by the insurer would have been most significant at this point. The distribution of returns seem to be peaked and left skewed for years 1 through 3, the distribution seems to become less peaked years 4 through 7 , and if the contracts are held for 10 years the skewness trends towards a normal distribution, but the distribution of gain and losses becomes more platykurtic.

The next section in Table 6 covers the period lasting from 1989 to 2006 (i.e. The Pre-Crisis Period). There are similar distributional issues found in this sample; however, the pricing of the home equity insurance product seems to have been much more plausible during this time frame. The breakeven cost of insurance was approximately $0.60 \%$; therefore, on a $\$ 100,000$ home the minimum charged to breakeven was $\$ 600$, which is less than $10 \%$ of the theoretical cost of coverage over the entire sample (i.e. from 1989 to 2013). During this time frame, 
the average cost of insurance is low and the maximum loss is relatively small when compared against the entire sample.

Table 6: Simulation

\begin{tabular}{|c|c|c|c|c|c|c|c|c|c|c|}
\hline \multicolumn{11}{|c|}{ Calculate the fixed premium that a hypothetical insurer would have to charge to remain solvent } \\
\hline \multicolumn{11}{|c|}{ From 1989 to 2013 the Breakeven Premium was $7.39 \%$} \\
\hline Statistic & 1 Year & 2 Year & 3 Year & 4 Year & 5 Year & 6 Year & 7 Year & 8 Year & 9 Year & 10 Year \\
\hline Sum & $2,246.10$ & $1,383.13$ & 708.71 & 168.24 & 0.00 & 184.46 & 564.96 & $1,243.77$ & $1,932.19$ & $2,333.71$ \\
\hline Mean & 7.18 & 4.60 & 2.44 & 0.60 & 0.00 & 0.72 & 2.30 & 5.29 & 8.63 & 10.96 \\
\hline Std Dev & 7.81 & 14.17 & 17.95 & 20.14 & 21.17 & 21.13 & 19.11 & 14.36 & 7.24 & 3.28 \\
\hline Min & -23.60 & -56.79 & -64.74 & -58.54 & -64.11 & -68.72 & -59.66 & -46.05 & -20.69 & 5.68 \\
\hline Max & 16.72 & 16.72 & 16.72 & 16.72 & 16.72 & 16.72 & 16.72 & 16.72 & 16.72 & 16.72 \\
\hline Skew & -2.41 & -2.81 & -2.37 & -1.94 & -1.89 & -2.05 & -2.14 & -2.30 & -2.08 & 0.01 \\
\hline Kurt & 6.79 & 7.57 & 4.70 & 2.37 & 2.25 & 2.96 & 3.40 & 4.20 & 4.80 & -0.95 \\
\hline$n$ & 313 & 301 & 290 & 279 & 268 & 257 & 246 & 235 & 224 & 213 \\
\hline \multicolumn{11}{|c|}{ From 1989 to 2006 the Breakeven Premium was $0.60 \%$} \\
\hline Statistic & 1 Year & 2 Year & 3 Year & 4 Year & 5 Year & 6 Year & 7 Year & 8 Year & 9 Year & 10 Year \\
\hline Sum & 82.08 & 31.09 & 13.64 & 0.00 & 7.33 & 22.98 & 33.70 & 79.39 & 108.24 & 103.20 \\
\hline Mean & 0.36 & 0.14 & 0.07 & 0.00 & 0.04 & 0.13 & 0.21 & 0.53 & 0.77 & 0.80 \\
\hline Std Dev & 0.97 & 1.31 & 1.58 & 1.80 & 1.73 & 1.69 & 1.51 & 0.94 & 0.30 & 0.30 \\
\hline Min & -4.69 & -4.28 & -5.91 & -6.01 & -5.60 & -5.44 & -5.30 & -3.81 & 0.45 & 0.46 \\
\hline Max & 1.35 & 1.35 & 1.35 & 1.35 & 1.35 & 1.35 & 1.35 & 1.35 & 1.35 & 1.35 \\
\hline Skew & -3.04 & -1.97 & -2.31 & -2.37 & -2.19 & -2.39 & -2.36 & -3.13 & 0.70 & 0.61 \\
\hline Kurt & 11.12 & 2.98 & 4.52 & 4.54 & 3.53 & 4.35 & 4.53 & 10.32 & -0.87 & -0.98 \\
\hline$n$ & 229 & 217 & 206 & 195 & 184 & 173 & 162 & 151 & 140 & 129 \\
\hline \multicolumn{11}{|c|}{ From 2007 to 2013 the Breakeven Premium was $20.85 \%$} \\
\hline Statistic & 1 Year & 2 Year & 3 Year & 4 Year & 5 Year & 6 Year & 7 Year & 8 Year & 9 Year & 10 Year \\
\hline Sum & $2,344.39$ & $1,254.76$ & 892.20 & 329.68 & 118.32 & 0.00 & 7.98 & 0.00 & 0.00 & 0.00 \\
\hline Mean & 31.68 & 20.24 & 17.49 & 8.24 & 4.08 & 0.00 & 1.14 & 0.00 & 0.00 & 0.00 \\
\hline Std Dev & 9.06 & 24.79 & 25.35 & 29.05 & 33.88 & 31.16 & 16.66 & 0.00 & 0.00 & 0.00 \\
\hline Min & -0.29 & -36.54 & -30.63 & -35.00 & -40.18 & -32.39 & -13.12 & 0.00 & 0.00 & 0.00 \\
\hline Max & 42.79 & 37.59 & 37.59 & 37.59 & 37.59 & 37.59 & 37.55 & 0.00 & 0.00 & 0.00 \\
\hline Skew & -2.95 & -1.45 & -1.05 & -0.31 & -0.22 & 0.38 & 2.24 & 0.00 & 0.00 & 0.00 \\
\hline Kurt & 8.43 & 0.28 & -0.74 & -1.75 & -1.94 & -1.96 & 5.54 & 0.00 & 0.00 & 0.00 \\
\hline$n$ & 74 & 62 & 51 & 40 & 29 & 18 & 7 & 0 & 0 & 0 \\
\hline
\end{tabular}

Table 6: Table 6 presents the descriptive statistics from a simulation of potential gains and losses experienced by a hypothetical insurer that provides insurance, based upon a fixed premium structure, constructed as a percent of the HPI over Time. The researchers partitioned the data into three periods: (a) The entire period, (b) The pre-crisis period, and (c) The postcrisis period. The simulation assumes that the insurer begins to write one contract per year starting at the beginning of the partitioned samples and either retains the premium or pays out a claim over 1, 2, 3, 4, 5, 6, 7, 8, 9, and 10-year rolling periods. The Sum Variable indicates the aggregate gain or loss in terms of Index Points.

In the last section of Table 6, the researchers present the summary statistics from the simulation of gains and losses experienced by the hypothetical insurer during the time period that covers the 2007 to 2013 period. The maximum loss would have been experienced in the 6th year of the contract in the post-crisis period when compared against the maximum loss in the 4th year of the pre-crisis period - this has implications for the potential design of the hypothetical insurance product. The standard deviation, average, and minimum and maximum observations experienced during this time horizon are obviously driving the cost of insurance up over the entire sample.

\section{RESULTS \& CONCLUSIONS}

What once seemed like the 'Greatest Idea Never Sold' (Zweig, J., 2011) does not seem as appealing as it once did. Shiller, R. and Weiss, A. (1999) and Goetzmann, W., Caplin, A., Hangen, E., Nalebuff, B., Prentce, E., Rodkin, J., Spiegel, M. and Skinner, T. (2003) provided a platform to explore the idea of home equity insurance. The concept of providing insurance to protect home owners evolved from municipally sponsored plans designed to protect homeowners residing within their municipality from negative externalities caused by racial integration in 
Oak Park, IL and from a depressed real estate market / economy in Syracuse, NY. These plans experienced limited success as measured through the participation rates in the plans.

Shiller and Weiss (1999) went to great lengths to explore what the appropriate risk transfer mechanism would look like. They examined both the concept of using derivatives contracts structured on an underlying home index and the concept of insurance provided by a company. The creation of the Case-Shiller Series of Home Price Indices, which are traded on public markets, have made the first option more realistic; however, the low volume of trading in derivative structures attached to these indices and the fact that protection would have to be structured as a derivative on the home price indices, which makes them less than desirable to the typical consumer, makes this option undesirable. On the other hand, Goetzmann, W., Caplin, A., Hangen, E., Nalebuff, B., Prentce, E., Rodkin, J., Spiegel, M. and Skinner, T. (2003) found in their evaluation of a pilot project, whose goal was to facilitate the transfer of risk from the homeowner to another party, that insurance regulators had trouble referring to a product such as this as insurance. The regulators rationale for not accepting them as insurance was because the insurance 'payoff' is based upon changing values of an associated index and that the homeowner did not have an insurable interest over the index.

The Home Value Insurance Company (HVIC) was the first company to issue insurance contracts structured to protect the homeowner against the decline in the value of their home. The company was licensed to issue insurance contracts in seven states and wrote contracts in three of these states. The majority of the contracts written were written in their state of incorporation (i.e. Ohio). From September 14, 2011 to August 28, 2012 the HVIC collected premiums of $\$ 31,344$ on an aggregate value of home prices of $\$ 32,419,400$. Moreover, they had structured the contracts so that they would only be liable for the first $25 \%$ decline in the value of the home prices; therefore, as a percentage of exposure they had collected $0.38 \%$ in of their notional exposure which was $\$ 8,104,850$. The company enforced a ten percent deductible for the first year of the contract and a five percent deductible on any claims on the contract's issued. Upon liquidation of the company, HVIC was order to pay out the greater of the index claim minus the five percent of the deductible or $\$ 500.00$ to the claimants. At this point, 57 of the homes that had policies written on them had experienced a loss greater than five percent of their home's value and a total value of $\$ 220,121.38$ was paid to the claimants (the losses came from contracts written in Ohio and Georgia).

The purpose of this analysis was to determine whether writing insurance policies on the starting value of the HPI is a prudent business idea. This paper evaluates three distinct periods: (a) The entire sample, (b) The precrisis period, and (c) The post-crisis period. The simulation that was run in this research project illustrates how significantly the cost of insuring home equity prices has changed over the two examination periods.

The first step in an evaluation of the structure of the HVIC insurance policies would be to determine if there is evidence that a company could provide insurance on the purchase price on the value of a home and remain solvent. This research project provides evidence that if the structure of the contracts were evaluated over the entire sample period the idea of home equity insurance is expensive. The estimated 'break-even' cost of insurance during the period lasting from 1989 to 2013 was $7.39 \%$ of the cost of the starting value of the HPI. When the researchers break up the sample into pre-crisis and post-crisis periods, it is evident that the cost of insurance becomes unstable during the post-crisis period.

This project finds that the slope of the regression of the price index on time changes markedly as U.S. Economy transitioned from the pre-crisis period to the post-crisis period. The slope of the regression in the pre-crisis period was $b_{1}(.0173)$ and the slope of the regression in the post-crisis period was $b_{2}(-0.239)$, these estimates were found to be statistically different using an $\alpha$ of less than .01 . The magnitude or the economic significance of the change was also significant, in contrast to an upward climbing trend identified in the pre-crisis period the HPI experienced a downward sloping trend in the post-crisis period. The question that this research project asks is how much does this change in the dynamics affect the pricing of protection on the HPI to the hypothetical insurer?

As the real estate market transitioned from a thriving market to a depressed market, the cost of insurance multiplied. In the pre-crisis period, the average cost of insurance was hovering around $0.60 \%$ of the cost of the property or the index. As the economy moved into the post-crisis period, the cost of insurance grew to over $20 \%$. 
This pushed the estimated cost of insurance over the entire period to $7.39 \%$. As time progressed, the cost of this product moved from affordable to unaffordable.

A deductible structure, similar to the one offered by HVIC, would not decrease the cost of insurance. The breakeven point in the pre-crisis period at a cost of $0.60 \%$ does not occur until year four; therefore, the premium structure offers little value to the insurance contract. Likewise, the breakeven point for the post-crisis period occurs after the after the proposed deductible structure ends, which in this case is year 6 . Over the entire period, the breakeven point occurred in year 5 . The deductible structure adds no value to the product unless it is stretched to year five.

As the U.S. Economy transitioned from the pre-crisis period to the post-crisis period, the cost of insurance increased to levels that were not previously experienced. The massive losses experienced in the HPI and, more importantly, in the value of home prices led to extreme paper losses on contracts written by the HVIC. The losses have only begun to make their way through the system (as evidenced by the lack of observations in the 8,9 , and 10 year periods in the post crisis period). The losses experienced in the post-crisis period substantially affect the plausibility of the concept of home equity insurance.

\section{AUTHOR INFORMATION}

\section{Zachary A. Smith, Ph.D.}

After serving four years in the United States Marine Corps, Zachary joined a major investment firm. His primary role on the team includes portfolio analysis, analytics, trading, and research related to market linked securities (structured products). Zachary earned his MBA in Finance from Capella University and his Ph.D. from Walden University. He has also taught several undergraduate and graduate-level finance and economics courses for Saint Leo University, Strayer University, Florida Institute of Technology, Averett University, The University of Phoenix, South University, Campbell University, and Mount Olive College. Email: zacharyasmith@ gmail.com (primary) or zachary.smith@saintleo.edu (Contact author)

\section{Alan Harper, Ph.D.}

Alan Harper Ph.D. is Program Director and Assistant Professor of Business Administration in the College of Business at South University. Dr. Harper Joined South University in March 2011 and is responsible for teaching in the College of Business and overseeing the Bachelors in Business Administration, the Masters in Business Administration and the Master in Leadership Programs. In addition, Dr. Harper is a Fulbright Candidate. Email: alaharper@southuniversity.edu or alaharper@gmail.com

\section{REFERENCES}

1. Case, K. (2008). The central role of home prices in the current financial crisis: How will the market clear? Brookings Papers on Economic Activity, Fall, pgs.161-193.

2. Goetzmann, William N., Caplin, Andrew, Hangen, Eric, Nalebuff, Barry J., Prentice, Elisabeth, Rodkin, John, Spiegel, Matthew I. and Skinner, Tom, Home Equity Insurance: A Pilot Project (May 2003). Yale ICF Working Paper No. 03-12.

3. Goetzmann, W., Peng, L., and Yen, J. (2012). The Subprime Crisis and House Appreciation, The Journal of Real Estate Finance and Economics, 44(1-2), pgs. 36-66.

4. Mazur, C. and Wilson, E. (2011). Housing Characteristics: 2010. U.S. Census Briefs. Issued October 2011.

5. Mikher, V. and Zemcik, P. (2009). Do house prices reflect fundamentals? Aggregate and panel data evidence. Journal of Housing Economics, 18, pgs. 140-149.

6. McKenzie, E. and Ruby, J. (2002). Reconsidering the Oak Park Strategy: The conundrums of integration. URL: http://astro.temple.edu/ ruby/opp/3qrpt02/finalversion.pdf.

7. Taylor v. Home Value Insurance Company (2012a). Application for Approval of the Rehabilitation plan for Home Value Insurance Company. Case Number: 12CV010970. August 31, 2012. Franklin County, OH.

8. Taylor v. Home Value Insurance Company (2012b). Motion for Order Terminating the Rehabilitation Plan for Home Value Insurance Company. Case Number: 12CV010970. December 21, 2012. 
9. The Joint Center for Housing Studies of Harvard University (2012). The State of the Nation's Housing 2012. URL: http://www.jchs.harvard.edu/sites/jchs.harvard.edu/files/son2012 bw.pdf. Accessed on 12/27/2012.

10. Shiller, R. and Weiss, A. (1999). Home Equity Insurance. Journal of Real Estate Finance and Economics, 19(1), pgs. 21-47. URL: http://cowles.econ.yale.edu/P/cp/p10a/p1007.pdf. Accessed on 12/28/2012.

11. Zweig, J. (2011). Hedging Your Home Value: The Greatest Idea Never Sold. The Wall Street Journal, May $14,2011$. 